\title{
Simulation of Traffic Flow to Analyze Lane Changes on Multi-lane Highways under Non-lane Discipline
}

\author{
Seelam Srikanth ${ }^{1 *}$, Arpan Mehar ${ }^{1}$, Kolisetty Guru Naga Venkata Praveen ${ }^{1}$ \\ ${ }^{1}$ Transportation Division, Department of Civil Engineering, National Institute of Technology, Warangal - 506004, Telangana, India \\ * Corresponding author, e-mail: ssseelamsrikanth@gmail.com
}

Received: 10 September 2016, Accepted: 22 September 2017, Published online: 30 January 2018

\begin{abstract}
The present study uses the microscopic traffic simulation flow model VISSIM for generating traffic flow data to obtain the essential parameters. Study calibrated and validated the VISSIM model based on the field data. Further, lane change behaviour is analyzed with homogeneous vehicle type traffic on four-lane, six-lane and eight-lane divided highways sections through VISSIM simulation model. The study finds the number of lane changes depends on traffic volume as well as on a number of lanes provided for a direction of travel. Lane change data was correlated with traffic volume, and the third-degree polynomial trend was found to be fitted on each type of simulated highway sections. A maximum number of lane changes and lane change at the capacity level of the volume are also quantified on simulated sections of four-lane, six-lane and eight-lane divided highways.
\end{abstract}

Keywords

mixed traffic, VISSIM, calibration, validation, lane changes

\section{Introduction}

India has second largest road network in the world with a total length of 4.6 million kilometres. The substantial increase in vehicular traffic growth on roads need a better system for transporting goods and people across the nation. Traffic volume in India is expected to increase in future years due to rapid growth in social and economic development. Realizing this fact that the Government of India (GOI) has taken new steps under National Highway Development Program (NHDP) to provide high-density corridors such as multilane highways and expressways for meeting the present and future needs of rapid, efficient, safe, and inter-connected highway networks. Multilane highways need serious thoughtfulness concerning the movement of traffic flow and capacity. Various lane changing and overtaking manoeuvres as take place on such highways which some leads to severe accidents.

Traffic flow behaviour on multilane highways is a complex phenomenon to understand and need better conceptual and logical way of data collection, analysis, and its interpretation. Various attempts made for modeling and the quantifying analogy of traffic flow behavior using empirical and analytical approach even under mixed traffic are successful but limited to field specific roadway and traffic conditions. The limitations arise due to practical difficulties in conducting extensive field experiments under wide variations of traffic flow parameters, non-availability of required field conditions, difficulty in experimenting with individual components in isolation, etc. As a solution to these practical problems, computer simulation has been proved to be a powerful tool in replicating complex traffic systems which allow experimentation to the basic traffic flow system. One such microscopic traffic simulation model is VISSIM which was developed in Germany based on the continuous work of Widemann on car-following behaviour. In the present study, VISSIM model is used to generate the traffic flow for a wide range from lower to higher levels and analyzed a number of lane changes on multilane highways. The capacity of four-lane, six-lane and eight-lane divided sections was also estimated with the help of a speed-flow diagram. The present study aims to analyze the capacity and lane changes for homogeneous vehicle type traffic stream by using pre-calibrated values of parameters $\mathrm{CC} 0$ and $\mathrm{CCl}$ under non-lane discipline. To attain the study objectives, influencing parameters in VISSIM model are calibrated and validated based on field data, and subsequently, lane 
changes of vehicles were analyzed on a different type of highway sections.

\section{Background Literature}

Extensive research has been carried out worldwide to understand the traffic flow behaviour under interrupted and uninterrupted conditions. One of the oldest study done by Greenshield (1934), where the author assumed a polynomial shape of the speed-flow curve obtained from field data based on calculated density. Afterwards, many empirical studies were performed using speed and flow data and proposed different alternative forms of speedflow curves under both heterogeneous and homogeneous. However, present review of literature is covering some of the most relevant studies on capacity and lane changes done in recent past decades based on field data and traffic simulation model.

\subsection{Studies based on field data}

Hoban (1987) performed the traffic study using field-collected traffic flow data to summarize the simple linear form of speed-volume relationship as an alternative to polynomial one, to determine highway capacity. Highway Research Board (HRB) of USA released the first Highway Capacity Manual (HCM) in 1965 that provided basic guidelines for capacity analysis. Later, the guidelines were revised several times as and when technological development took place into vehicle manufacturing and infrastructure industries. Indonesian IHCM (1997) was developed with certain guidelines to model speed and flow data for determining capacity values. HCM (2010) have provided the shape of speed-flow curves at different free flow speeds where stream speeds are assumed to be insignificant with an increase in volume. A substantial amount of studies were also performed under mixed traffic conditions. Some of the relevant studies are discussed in this section. Tanaboriboon and Aryal (1990) studied the effect of vehicle size on highway capacity in Thailand. It was found that medium-size vehicles do not affect the lane capacity. Roadway capacity was estimated to be $2100 \mathrm{PCU} /$ hour/lane which was $9 \%$ more than the basic capacity adopted on highways in Thailand. Yang and Zhang (2005) established the fundamental flow relationships based on extensive field traffic flow survey data collected on multilane highways in Beijing. The average capacity per lane was found to reduce with the addition of an extra lane to a highway. They suggested ideal capacity values for four-lane, six-lane, and eight-lane divided highways as 2250, 2100 and $2000 \mathrm{PCU} /$ hour/lane. Sinha et al., (2012) performed a comparative study on the effect of motorcycle proportions on the capacity of four-lane urban roads in India and Thailand. Linear regression analysis was carried out to propose the relationship between capacity and motorcycle percent share for the highways in both countries. Mehar et al., (2014) determine the capacity of four-lane divided highway under mixed traffic conditions. Authors analyzed field data and suggested the capacity of four-lane divided highway with the paved shoulder as $5227 \mathrm{PCU} / \mathrm{hr} /$ dir. Many authors related capacity of a roadway with lane changing and overtaking behaviour. Laval et al., (2008) introduced a framework to solve vehicle lane-changing problem using a macroscopic theory inside microscopic models. Knoop et al., (2012) proposed a methodology to quantify lane changes and tested with the field observed data. Authors suggested the proposed lane change measurement can be used to quantify the effect of lane changes on the capacity. Jin (2010) analyzed macroscopic characteristics of lane changing on multilane highways. The author revealed that angles of lane changing of the vehicle are highly related to the density of traffic stream and found that the lane changes have a significant effect on the capacity of multilane highways.

\subsection{Studies based on simulation}

The analysis and modeling of traffic flow behavior using traffic flow simulation have been very popular during past few decades. The traffic simulation models are very vital in resolving the complexities arrive in the modeling of macroscopic and microscopic traffic flow behaviours. Some of the important studies based on simulation model are discussed in this subsection. Chitturi and Benekohal (2008) presented a procedure for calibration of default parameters in VISSIM and found that the driver behaviour parameters namely CC0 (standstill distance) and CC1 (time headway) influences the capacity values and also for low-speed conditions, the impact of $\mathrm{CC} 0$ on capacity was found significant but as the speed increases its effect diminishes while the impact of CC1 increases. Park and Won (2006) described a procedure for calibration of default parameters in VISSIM and found that the safety distance reduction factor defined for the link indicates the aggressiveness of the driver. Menneni et al., (2008) also performed the parameter calibration of VISSIM using optimization algorithm and developed a new methodology for assessing the capacity by matching the speed-flow graphs from the field as well as from simulation. Park and Kwak (2011) 
also evaluated the results of calibration and validation procedure by comparing the distribution of simulation output with field data. Mehar et al., (2013) investigated the sensitivity of different driving behaviour parameters given in VISSIM model on capacity. Authors identified two parameters in the Widemann 99 model as CC0 and CC1 affecting the simulated capacity significantly. Velmurugan et al., (2010) also used traffic simulation model VISSIM and plotted speed-flow curves on four-lane, six-lane and eight-lane divided highways and reported their directional capacity values as $5574 \mathrm{PCU} / \mathrm{hr}, 7733 \mathrm{PCU} / \mathrm{hr}$, and 9796 PCU/hr respectively. Authors analyzed capacity of multilane highways with and without lane changing behaviour.

\section{Field data}

Field data were collected for present study at two different locations on four-lane divided National Highway (NH) known as NH 163, Warangal to Hyderabad, India. The traffic flow data on the first section (Section I) was collected near Bibinagar village and on second section (Section -II) near Ghanpur village. Both the highways are having paved shoulders in good conditions with $1.5 \mathrm{~m}$ width and differ concerning access control. The snapshot of Section I is shown in Fig. 1. Field data collected in the section-I used for development of VISSIM model whereas data collected on section II used for validation of VISSIM model.

Traffic flow data on sections were collected by using the video-graphic method with the help of marking $50 \mathrm{~m}$ trap-length in one direction of travel. Data collection was performed for 4 hours from $8 \mathrm{AM}$ to $12 \mathrm{PM}$ on a typical weekday under clear weather conditions. The collected data were then extracted with the aid of semi-automated data extraction software to obtain classified traffic volume counts and mean speed of vehicles at every 5-minute interval. All the vehicles were classified into five categories namely, Standard car (CS), big utility car (CB), Twowheeler (2W), Three-wheeler (3W), and Heavy Vehicle (HV). Standard car (CS) is defined as a Passenger car in the present analysis.

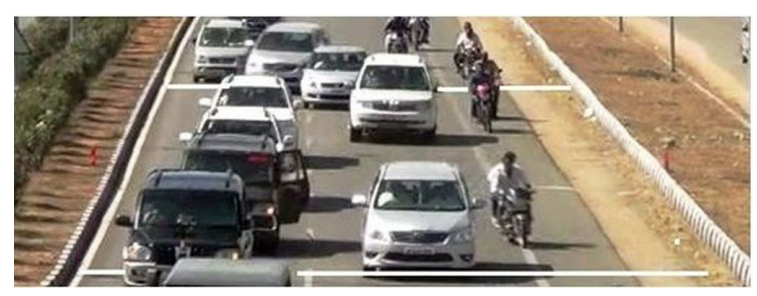

Fig. 1 Snapshot of four-lane divided highway (Section-I)

\section{Field data analysis}

The speed of a vehicle was determined by noting down the time taken by a vehicle to traverse the trap length using a stopwatch of $0.01 \mathrm{~s}$ accuracy. Speeds of an individual category of vehicles were extracted, and the distribution profiles were created. The average speed of different vehicles and their traffic composition are given in Table 1.

Field traffic volume measured in veh/hr and further converted into passenger car equivalency units using the method of dynamic PCU estimation as proposed by Chandra and Kumar (2003). PCU of $i^{\text {th }}$ type of vehicle was estimated by using Eq. (1).

$$
\operatorname{PCU}_{\mathrm{i}}=\left(\mathrm{V}_{\mathrm{c}} / \mathrm{V}_{\mathrm{i}}\right) /\left(\mathrm{A}_{\mathrm{c}} / \mathrm{A}_{\mathrm{i}}\right)
$$

Where, $\mathrm{PCU}_{\mathrm{i}}$ is the passenger car unit of the $\mathrm{i}^{\text {th }}$ type of vehicle, $V_{c}$ is the speed of standard car in $\mathrm{km} / \mathrm{hr}, \mathrm{V}_{\mathrm{i}}$ is the speed of $\mathrm{i}^{\text {th }}$ vehicle type in $\mathrm{km} / \mathrm{hr} ; \mathrm{A}_{\mathrm{c}}$ is the projected area of the small car in $\mathrm{m}^{2} ; \mathrm{A}_{\mathrm{i}}$ is the projected area of the $i^{\text {th }}$ vehicle type in $\mathrm{m}^{2}$.

The stream speed was calculated at each 5 min interval by taking the weighted average speed of all vehicle categories. The speed-flow relationship was developed from field data to determine a capacity of the study section. The speed-flow field data was fitted to a theoretical Greenshields polynomial speed-flow model by assuming a straight line relationship between calculated density and stream speed. This theoretical model yielded the capacity of the four-lane divided highway as $5267 \mathrm{PCU} / \mathrm{hr} / \mathrm{dir}$.

Table 1 Speed data and traffic composition on both sections

\begin{tabular}{|c|c|c|c|c|}
\hline \multirow{2}{*}{$\begin{array}{l}\text { Road } \\
\text { section }\end{array}$} & \multirow[t]{2}{*}{ Vehicle type } & \multicolumn{2}{|c|}{$\begin{array}{l}\text { Speed parameters } \\
\qquad(\mathrm{Km} / \mathrm{hr})\end{array}$} & \multirow{2}{*}{$\begin{array}{c}\text { Traffic } \\
\text { composition }(\%)\end{array}$} \\
\hline & & Average & St. dev & \\
\hline \multirow{5}{*}{ Section-I } & $\mathrm{CS}$ & 69.1 & 11.2 & 31 \\
\hline & $\mathrm{CB}$ & 70.2 & 11.3 & 7 \\
\hline & $2 \mathrm{~W}$ & 51.3 & 10.7 & 46 \\
\hline & $3 \mathrm{~W}$ & 42.7 & 7.6 & 5 \\
\hline & $\mathrm{HV}$ & 46.9 & 9.2 & 11 \\
\hline \multirow{5}{*}{ Section-II } & $\mathrm{CS}$ & 65.3 & 15.1 & 11 \\
\hline & $\mathrm{CB}$ & 66 & 14.1 & 10 \\
\hline & $2 \mathrm{~W}$ & 52.1 & 13.1 & 43 \\
\hline & $3 \mathrm{~W}$ & 39.5 & 8.8 & 22 \\
\hline & HV & 47.2 & 8.5 & 14 \\
\hline
\end{tabular}




\section{Simulation analysis}

Microscopic traffic flow simulation model VISSIM has been used in the present analysis to perform simulation analysis. VISSIM is a microscopic, time step and behaviour based simulation model developed to model freeways, urban traffic, and public transit operations. It performs trajectory-based analysis that utilizes psycho-physical driver behaviour developed by Wiedemann. The model is developed in Germany and contains certain specific parameters which need to be checked before performing simulation analysis. Simulation analysis was performed in present study using the data collected on two different sections in the field. Field data collected on section-I was used for development of the base model network in VISSIM and model calibration. Whereas, field data collected on section-II was used for validation of the model.

For the development of the base model, a straight link of $1.4 \mathrm{~km}$ was created in VISSIM where only $1.0 \mathrm{~km}$ of the center part was considered for data analysis and $0.2 \mathrm{~km}$ length on either side of the stretch was considered as buffer link. The link was created with two lanes of $3.5 \mathrm{~m}$ width and shoulder lane of $1.5 \mathrm{~m}$. To measure the simulated speed a section of $50 \mathrm{~m}$ was created at the appropriate distance away from the point of vehicle input. The lateral and overtaking behaviours in VISSIM were modified as per left sided rule to truly replicate the non-lane based traffic conditions. Primarily, the model was run based on its default setting of parameters with basic field input data such as desired speed of each vehicle types and volume in veh/hr as per field observation. The simulation data was extracted for one $\mathrm{hr}$ and output was compared with the field data. The comparison was made on the basis of field traffic volume and speed distribution profile of vehicles. The comparison of traffic volume and speed profile of one of the vehicle types is depicted in Fig. 2. Field traffic volume obtained at $5 \mathrm{~min}$ interval was compared with simulated volume at the same interval. Simulation output based on the default parameters settings has resulted in large differences between the field data, and it can be inferred that the VISSIM at default values of parameters not able to reflect field traffic flow behaviour. Therefore, model required the fine-tuning of volume and
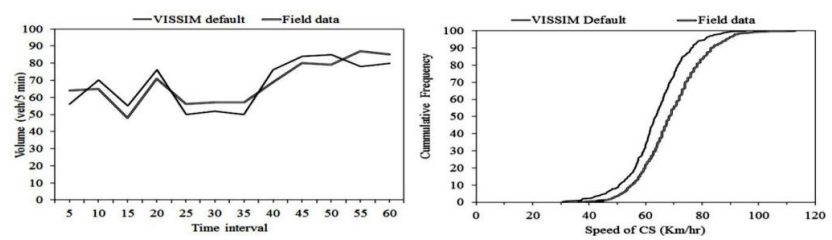

Fig. 2 Comparison of traffic volume and speed profile speed related parameters to obtain the minimum difference in a field and simulated outputs.

\section{Calibration of VISSIM}

It has been observed from the review of literature that VISSIM consist of some simulation parameters which have the direct influence on traffic flow, speed and capacity (Chitturi and Benekohal, 2008). VISSIM works based on car-following driver behaviour model developed by Widemnann. Some of the parameters have been found to be influential at capacity, and some of them affect the behaviour of the driver only under car-following situations. Apart from driving behaviour model, VISSIM consists of simulation parameter such as Random Seed number (RSN). The default value of RSN parameter is 42 and any change in RSN values significantly affect the distribution of vehicle generation into the network or in other words; it changes the inter-arrival time of vehicles. Therefore, it was decided to observe the change in RSN value on traffic volume measurement at a point on a four-lane divided section. Five different values of RSN were chosen (40, 41, $42,43,44)$ and simulation was performed using field data inputs. The traffic volume found to be varied at different RSN and Mean absolute percentage error (MAPE) were calculated to compare simulated and field traffic volume for entire 4 hrs. The RSN values 41, 42, 43 and 44 have shown the large value of MAPE in compared to 40, and therefore, the value with least absolute percentage error was selected for further analysis. The comparison of simulated and field traffic volume and its MAPE estimated at different RSN values are shown in Fig. 3 (a) and (b).

The present study is further targeted to the estimation of capacity by developing speed-flow diagram. Among ten different driver behaviour parameters (CC0 to $\mathrm{CC} 9)$ given in Wiedemann Model 99 only two of them namely; $\mathrm{CC} 0$ (standstill distance) and $\mathrm{CC1}$ (time headway) are found to be significant as the traffic flow reaches to capacity (Mehar et al., 2013). These are the two parameters
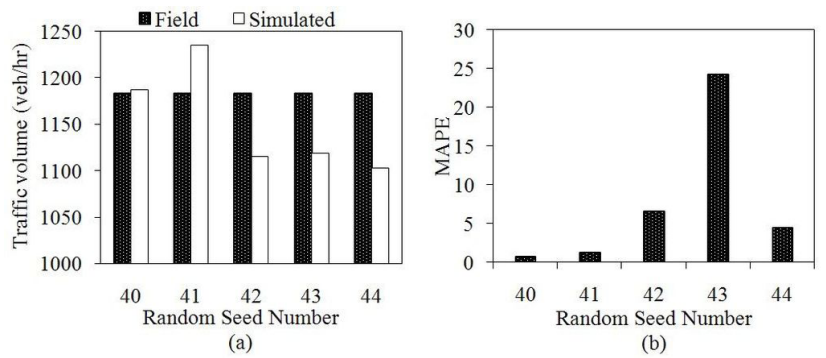

Fig. 3 (a) Traffic volume at different RSN, (b) MAPE at different RSN 
which govern the safety distance between the vehicles in the simulation model. Default values of CC0 and CC1 parameters are $1.5 \mathrm{~m}$ and $0.9 \mathrm{sec}$ respectively. Capacity obtained from default values of these two parameters may not be reliable unless calibration is performed using field data. The present study refers to the previous simulation study performed by Mehar et al. (2014) under mixed traffic on the calibration of VISSIM parameters influencing the capacity of four-lane divided highway. The outcome of the calibration was based on the sensitivity analysis performed by considering multiple parameter analysis. Authors calibrated the parameters for homogeneous vehicle type traffic situations such as 'All CS', 'All CB', 'All 2W', 'All $3 \mathrm{~W}$ ', 'All $\mathrm{HV}$ ' and suggested appropriate values of $\mathrm{CCl}$ and $\mathrm{CC} 0$. The present study uses the values of $\mathrm{CCO}$ and CC1 parameters suggested by Mehar et al. (2014) for simulating 'All CS' type traffic situation in VISSIM to obtain capacity and to quantify a number of lane changes on fourlane, six-lane, and eight-lane divided highway sections. The calibrated values of $\mathrm{CC} 0$ and $\mathrm{CC} 1$ parameters are shown in Table 2 . The values of $\mathrm{CC} 0$ and $\mathrm{CC} 1$ parameters were given as input to driver behavior model by creating separate driving behavior set for each vehicle types and kept all the other parameters as default (CC2 to CC9). The input values of vehicle type driving behavior parameter sets along with new link behavior type are shown in Fig. 4.

Speed-flow curve developed through simulation gives a capacity value of four-lane divided road as $5334 \mathrm{PCU} / \mathrm{hr} /$ dir with paved shoulders. Fig. 5 shows the comparison of speed-flow curves from a field and simulated data. Capacity determined through simulation was also compared with field capacity (5267 PCU/hr/dir) and the difference between the two capacity values is found as $1.25 \%$. It can be inferred that the calibration of VISSIM model parameters have been performed successfully as the model can reflect field capacity under an acceptable range of error (less than 5\%).
Table 2 VISSIM parameters for homogeneous traffic stream

\begin{tabular}{lccc}
\hline \multirow{2}{*}{$\begin{array}{l}\text { Homogeneous vehicle } \\
\text { type }\end{array}$} & $\begin{array}{c}\text { Simulated capacity } \\
(\mathrm{veh} / \mathrm{hr})\end{array}$ & \multicolumn{2}{c}{ Calibrated values } \\
\cline { 3 - 4 } & 4950 & 1.17 & 1.1 \\
\hline $\mathrm{CS}$ & 3385 & 1.5 & 1.4 \\
$\mathrm{CB}$ & 9540 & 0.3 & 0.3 \\
2W & 2950 & 1.5 & 0.9 \\
3W & 1245 & 2.4 & 1.7 \\
$\mathrm{HV}$ & & &
\end{tabular}

\section{Validation}

Validation of the VISSIM parameters was performed using another set of field data collected on a four-lane divided inter-urban highway with partially access control having paved shoulders. The speed and traffic composition of this section have been provided in Table 1. Speed and traffic volume data collected in the field are given as basic input to VISSIM.

The field and simulated average speed of each vehicle types were also compared for validation by estimating Root Mean Square Error (RMSE) of average speeds. The RMSE value was estimated as 2.07 which is also considered as satisfactory. The comparison for average speed data of field and simulated for each vehicle type is shown in Fig. 6. Simulated traffic volume output was also compared with the field volume which has shown only $5 \%$ absolute percentage error.

Mean absolute percentage error (MAPE) was estimated to compare simulated and field observed speed distribution parameters and the results were found under the satisfactory limit. Simulated speed distribution profiles were also created for each vehicle type and compared with the profiles developed with field speed data. The comparison is shown in Fig. 7.

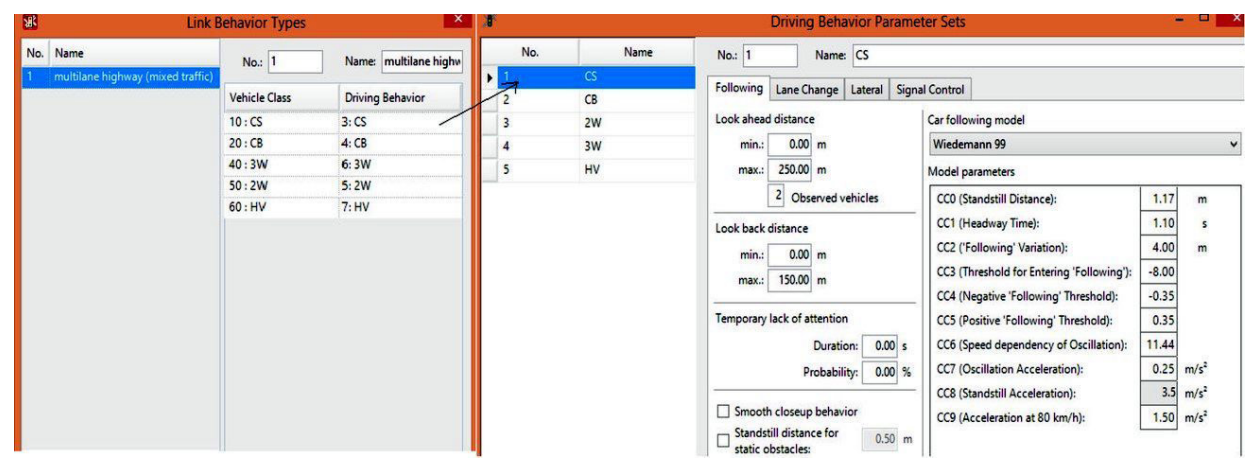

Fig. 4 Created a new link behavior type with inputs of vehicle type based $\mathrm{CC} 0$ and $\mathrm{CC} 1$ parameters 


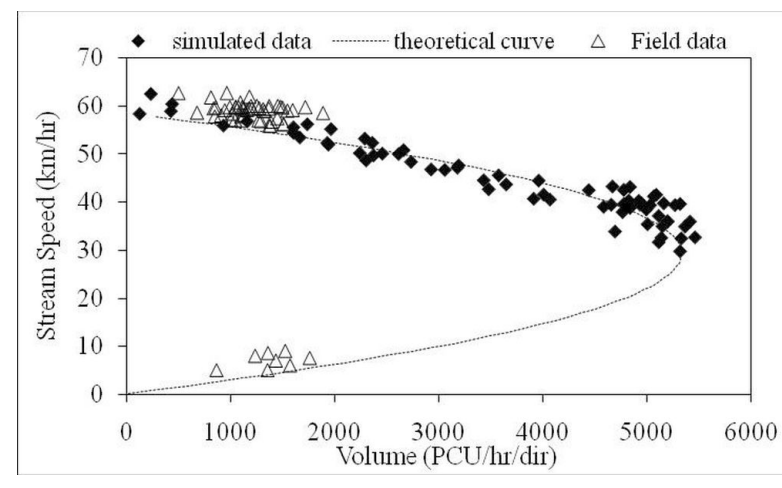

Fig. 5 Speed-flow curves from field and simulated data

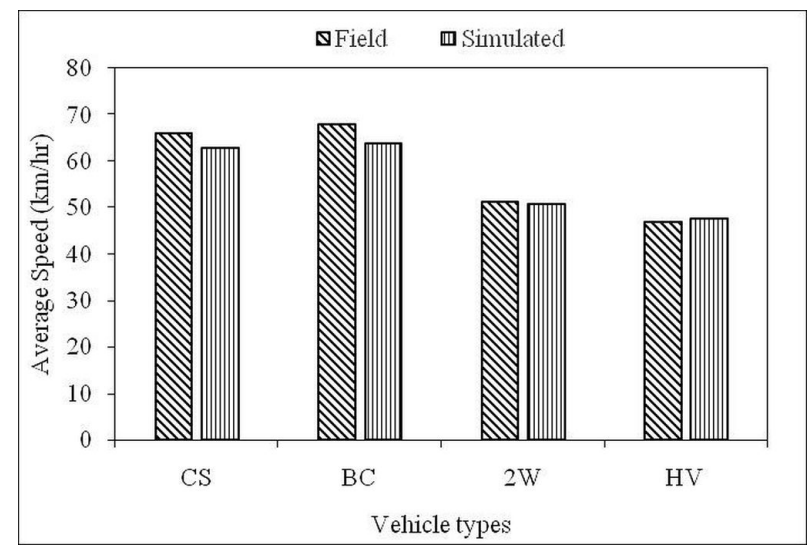

Fig. 6 Comparison of average speeds from field and simulation model

\section{Analysis of lane change}

Lane change behaviour of vehicles represents the macroscopic traffic flow behaviour and influences the operational characteristics on the highway very substantially. Lane changing is sometimes necessary for overtaking and crossing a weaving segment on a roadway. Lane changing of vehicles creates voids or spaces within traffic streams which tend to increase the stream speeds and capacity. The study analyses lane change the behaviour of vehicles on the multilane highway using microscopic simulation model VISSIM.

To quantify a number of lane changes, VISSIM was run with homogeneous type traffic situations on the four-lane divided road, in one direction of travel (two-lanes, $3.5 \mathrm{~m}$ per lane width). 'All CS' traffic stream was simulated in VISSIM with input values of $\mathrm{CC} 0$ and $\mathrm{CC} 1$ as suggested in Table 2. Traffic volume input was also varied from low to higher levels and simulation runs were performed for 2 hrs. Lane change data was extracted from the output file at $10 \mathrm{~min}$ interval. Traffic volume and speed data also extracted from the same output file, and similar exercise was performed for six-lane and eight-lane divided section.

Fig. 8 shows the number of the lane change in one direction of travel on four-lane, six-lane and eight-lane
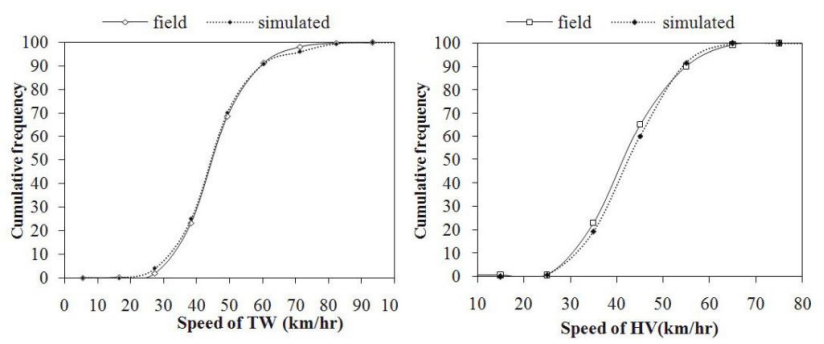

Fig. 7 Comparison of simulated and field speed cumulative frequency profiles

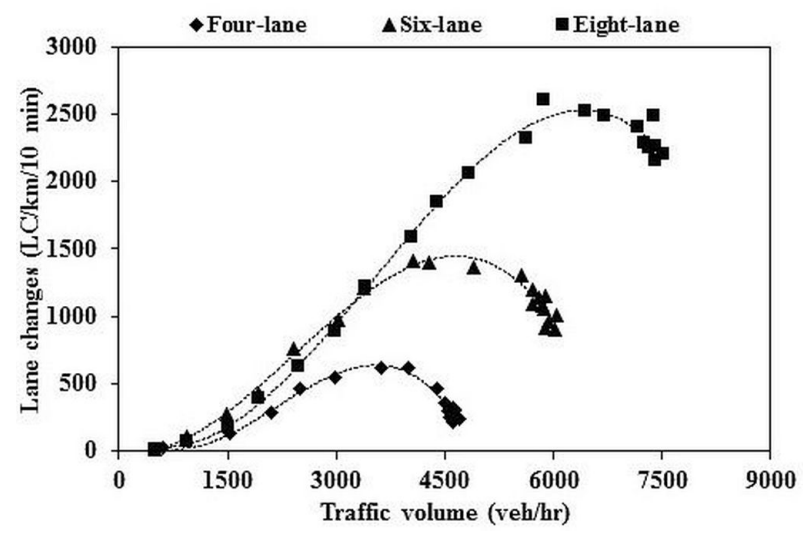

Fig. 8 Numbers of lane changes at varying traffic volume

simulated divided sections at different volume levels. The relationships presented above are also providing the idea of finding a maximum possible number of lane changes on each type of highway section. The third-degree polynomial curve was found to be the best fit for lane change data when it correlated with traffic volume. A maximum number of lane changes on four-lane, six-lane and eight-lane divided highway sections were quantified by observing the peak of the fitted curve. Traffic flow and speed data were analyzed, and speed-volume curve developed for each type of highway section to determine capacity. For example, the speed-volume curve for "All CS" type traffic flow on the six-lane divided highway is shown, with a number of lane changes in Fig. 9. Simulated capacity (maximum volume) on four-lane, six-lane and eight-lane divided highways was determined under 'All CS' type traffic situation. The number of lane changes on each highway section at the capacity level of the volume is also estimated. The estimated values of a number of lane changes at simulated capacity values are given for four-lane, six-lane and eight-lane divided sections in Table 3. It is observed that the number of lane changes restricted at a capacity level of volume and no more lane changes are observed beyond 


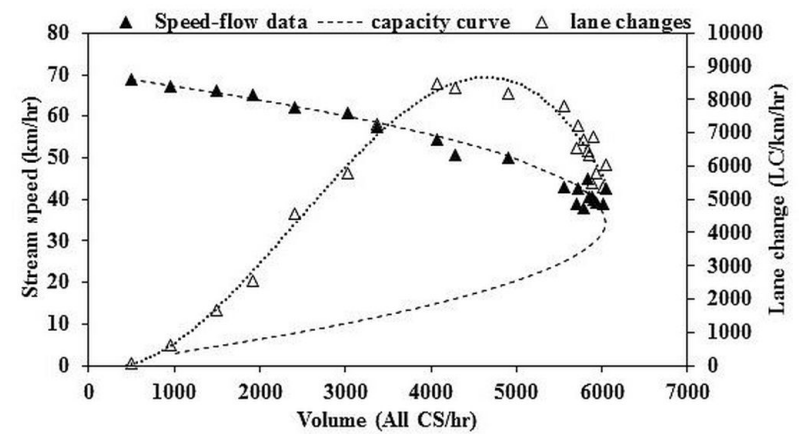

Fig. 9 Lane change and capacity curves on six-lane divided section

Table 3 Number of lane changes on multilane highways

\begin{tabular}{lccc}
\hline $\begin{array}{l}\text { Highway } \\
\text { type }\end{array}$ & $\begin{array}{c}\text { Capacity } \\
(\text { All CS/hr) }\end{array}$ & $\begin{array}{c}\text { Lane changes at } \\
\text { capacity (LC/km/hr) }\end{array}$ & $\begin{array}{c}\text { Maximum lane } \\
\text { change (LC/km/hr) }\end{array}$ \\
\hline Four-lane & 4800 & 1860 & 3600 \\
Six-lane & 6042 & 6013 & 8484 \\
Eight-lane & 8020 & 12960 & 15156 \\
\hline
\end{tabular}

capacity. The phenomenon happens due to the reason that the drivers feel difficulty in finding space or lane and tends to follow others vehicles on the same lane when the volume reaches to capacity. An interesting phenomenon is also observed when the number of lanes increased, total capacity also increased (regardless of lanes), but it found to be decreased when estimated per lane basis. It can be inferred that as a number of lanes increase the frequency of lane change also increases and hence it affects the per lane capacity. The capacity per lane for a different simulated section is shown in Fig. 10.

\section{Conclusions}

Traffic flow and speed data collected at four-lane divided highway sections are analyzed to estimate capacity. The estimated capacity of four-lane divided highway with paved shoulders was found as $5267 \mathrm{PCU} / \mathrm{hr} / \mathrm{dir}$. Traffic data obtained from the field was used as input for the development of base network model in VISSIM. The fine-tuning of VISSIM desired speed distribution parameters and RSN was performed using field data. The marginal variation in traffic volume was found with different RSN values. RSN value as 40 was decided to keep for further simulation analysis as it was giving the least error. A separate link behavior type was created in the model and inputs for driving behavior parameters such $\mathrm{CC} 0$ and $\mathrm{CC} 1$ were given separately for each vehicle types. Simulated capacity based on field data inputs determined as close as

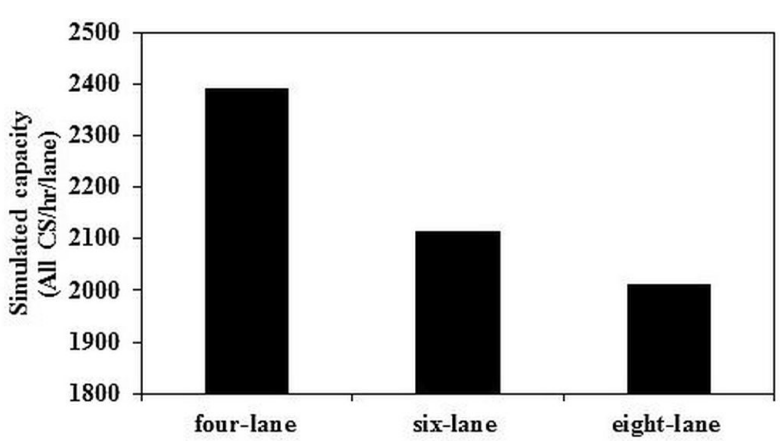

Fig. 10 Capacity per lane on different simulated sections

to field capacity. The difference between the capacity was only 1.25 percent. Validation of VISSIM model was also performed with the different set of field data by taking speed and volume as the measure of effectiveness.

VISSIM was further run with calibrated link network to quantify a number of lane changes. The simulation runs were performed with homogeneous vehicle type situation such as 'All CS' and with a different number of lanes. The number of lane changes estimated on varying number of lanes showed correlation with traffic volume. Third-degree parabola found as best fit for presenting lane change behavior under lower to higher volume levels. It was observed that the number of lane changes increased with volume to some extent but further decreased at higher volume level. But no significant change in lane changes has been observed between six-lane and eight-lane divided sections when traffic volume is less than $3500 \mathrm{All} \mathrm{CS} / \mathrm{hr}$. The value of maximum lane changes was also estimated in case of four-lane, six-lane and eight-lane divided sections. The number of lane changes is found to be stagnating when traffic volume reaches capacity. At capacity, the opportunity of the lane change is restricted due to the availability of less free space. Even very small numbers of forced lane change maneuvers may be caused sudden breakdown of flow which led to the unstable condition. It has been observed that the number of lane changes increases with a number of lanes. Still, the capacity of a roadway estimated as per lane is found to decrease with increase in a number of lanes. It is true that the addition of a lane will provide more opportunity to the vehicles to change lanes but the same times causes a reduction in traffic stream speed under non-lane disciple which results in a reduction of per lane capacity. In future, the lane change behaviour will be analyzed under mixed traffic situation to observe its effect on the capacity of multilane highways. 


\section{References}

Chandra, S., Kumar, U. (2003) "Effect of lane width on capacity under mixed traffic conditions in India", Journal of Transportation Engineering, ASCE, 129, pp. 155-160. https://doi.org/10.1061/(ASCE)0733-947X(2003)129:2(155)

Chitturi, M. V., Benekohal, R. F. (2008) "Calibration of VISSIM for the freeway", In: Proceeding of 87th TRB Annual Meeting, TRB, National Research Council, Washington D.C., pp. 1-10.

Greenshields, B. D. (1934) "A study of traffic capacity", Proceeding of Highway Research Record Board, 14, pp. 448-477.

Highway Capacity Manual (2010) "Transportation Research Board of the National Academies", 5th ed., Vol. 2, Washington DC., USA.

Hoban, C. J. (1987) "Evaluating traffic capacity and improvements to road geometry", The World Bank Technical Paper Number 74, Washington D. C. [online] Available at: http://documents.worldbank.org/curated/en/616111468184147999/pdf/ WTP74000Proced0nts0to0road0geometry.pdf [Accessed: 02 September 2016]

Indonesian Highway Capacity Manual (IHCM), Directorate General, Bina Marga, Republic Indonesia (1997) [online] Available at: www. ajisuraji/wp-content/uploads/2011/12/IHCM-1997-IndonesianHighway-Capacity-Manual.pdf [Accessed: 05 September 2016]

Laval, J. A., Leclercq, L. (2008) "Microscopic modeling of the relaxation phenomenon using a macroscopic lane-changing model", Transportation Research Part B: Methodological, 42(6), pp. 511-522. https://doi.org/10.1016/j.trb.2007.10.004

Jin, W. L. (2010) "Macroscopic characteristics of lane-changing traffic", Transportation Research Record: Journal of the Transportation Research Board, 2188, pp. 55-63. https://doi.org/10.3141/2188-07

Knoop, V. L., Hoogendoorn, S. P., Yasuhiro, S., Buisson, C. (2012) "Quantifying the number of lane changes in traffic: empirical analysis", Transportation Research Records, Journal of the Transportation Research Board. 2278, pp. 31-41. https://doi.org/10.3141/2278-04

Mehar, A., Chandra, S., Velmurugan, S. (2013) "Passenger car units at different levels-of-service for capacity analysis of multilane divided highways", ASCE, Journal of Transportation Engineering, 140(1), pp. 81-88.

https://doi.org/10.1061/(ASCE)TE.1943-5436.0000615
Mehar, A., Chandra, S., Velmurugan, S. (2014) "Highway capacity through VISSIM calibrated for mixed traffic conditions", KSCE Journal of Civil Engineering, 18(2), pp. 639-645. https://doi.org/10.1007/s12205-014-0440-3

Menneni, S., Sun, C., Vortisch, P. (2008) "Microsimulation calibration using speed-flow relationships", Transportation Research Record: Journal of the Transportation Research Board, 2088, pp. 1-9. https://doi.org/10.3141/2088-01

Park, B. B., Won, J. (2006) "Simulation model calibration and validation Phase II: Development of implementation handbook", [online] Available at: http://www.virginiadot.org/vtrc/main/online reports/pdf/07-cr5.pdf [Accessed: 01 September 2016]

Park, B. B., Kwak, J. (2011) "Calibration and validation of TRANSIMS micro simulator for an urban arterial network", KSCE Journal of Civil Engineering, KSCE, 15(6), pp. 1091-1100. https://doi.org/10.1007/s12205-011-1002-6

Sinha, S., Taneerananon, P., Chandra, S. (2012) "A comparative study of effect of motorcycle volume on capacity of four-lane urban roads in India and Thailand", Journal of Eastern Society of Transportation and Traffic Studies(JSTS), 3(4), pp. 52-62.

Shukla, S., Chandra, S. (2011) "Simulation of mixed traffic flow on fourlane divided highways", Journal of the Indian Roads Congress, 72(1), pp. 55-69.

Tanaboriboon, Y., Aryal, R. (1990) "Effect of vehicle size on highway capacity in Thailand", Journal of Transportation Engineering, $116(5)$, pp. 658-666 https://doi.org/10.1061/(ASCE)0733-947X(1990)116:5(658)

Velmurugan, S., Errampalli, M., Ravinder, K., Sitaramanjaneyulu, K. (2010) "Critical evaluation of roadway capacity of multilane highspeed corridors under heterogeneous traffic condition through traditional and microscopic simulation model", Journal of Indian Roads Congress, 566, pp. 235-264. [online] Available at: http:// www.crridom.gov.in/sites/default/files/irc-paper-no.566-papergiven-bihar-pwd-medal-by-irc.pdf [Accessed: 01 September 2016]

Yang, X., Zhang, N. (2005) "The marginal decrease of lane capacity with the number of lanes on highway", Proceeding of International Conference of Eastern Asia Society for Transportation Studies (EASTS), 5, pp. 739-749. [online] Available at: http://www.easts. info/on-line/proceedings_05/739.pdf [Accessed: 02 September 2016] 